\title{
Article \\ COVID-19 Peritraumatic Distress as a Function of Age and Gender in a Spanish Sample
}

\author{
María Pilar Jiménez ${ }^{1}$, Jennifer A. Rieker ${ }^{1}$, José Manuel Reales ${ }^{2}$ and Soledad Ballesteros ${ }^{1, *}$ \\ 1 Departamento de Psicología Básica II, Universidad Nacional de Educación a Distancia, \\ C/Juan del Rosal 10, 28040 Madrid, Spain; mpjimenez@psi.uned.es (M.P.J.); jrieker@psi.uned.es (J.A.R.) \\ 2 Departamento de Metodología para las Ciencias Sociales, Universidad Nacional de Educación a Distancia, \\ C/Juan del Rosal 10, 28040 Madrid, Spain; jmreales@psi.uned.es \\ * Correspondence: sballesteros@psi.uned.es
}

Citation: Jiménez, M.P.; Rieker, J.A.; Reales, J.M.; Ballesteros, S. COVID-19 Peritraumatic Distress as a Function of Age and Gender in a Spanish Sample. Int. J. Environ. Res. Public Health 2021, 18, 5253. https:// doi.org/10.3390/ijerph18105253

Academic Editors: Paul B. Tchounwou and María Crespo

Received: 24 March 2021

Accepted: 13 May 2021

Published: 14 May 2021

Publisher's Note: MDPI stays neutral with regard to jurisdictional claims in published maps and institutional affiliations.

Copyright: (c) 2021 by the authors. Licensee MDPI, Basel, Switzerland. This article is an open access article distributed under the terms and conditions of the Creative Commons Attribution (CC BY) license (https:// creativecommons.org/licenses/by/ $4.0 /)$.

\begin{abstract}
The sudden outbreak of the COVID-19 pandemic has profoundly altered the daily lives of the population with dramatic effects caused not only by the health risks of the coronavirus, but also by its psychological and social impact in large sectors of the worldwide population. The present study adapted the COVID-19 Peritraumatic Distress Index (CPDI) to the Spanish population, and 1094 Spanish adults (mean age 52.55 years, 241 males) completed the Spanish version in a cross-sectional online survey. To analyze the factorial structure and reliability of the CPDI, we performed an exploratory factor analysis (EFA) followed by a confirmatory factor analysis (CFA) on the Spanish sample. The effects of gender and age on the degree of distress were analyzed using the factorial scores of the CPDI as the dependent variables. Results showed that, after rotation, the first factor (Stress symptoms) accounted for 35\% of the total variance and the second factor (COVID-19 information) for $15 \%$. Around $25 \%(n=279)$ of the participants experienced mild to moderate distress symptoms, $16 \%(n=179)$ severe distress, and about $58 \%(n=636)$ showed no distress symptoms. Women experienced more distress than men $(p<0.01)$, and distress decreased with age $(p<0.01)$. We conclude that the CPDI seems a promising screening tool for the rapid detection of potential peritraumatic stress caused by the COVID-19 pandemic.
\end{abstract}

Keywords: COVID-19 Peritraumatic Distress Index; cluster analysis; exploratory factor analysis (EFA); confirmatory factor analysis (CFA); age differences; psychological distress; psychological impact

\section{Introduction}

The outbreak of a new coronavirus has caused a "tsunami" that has profoundly altered the daily lives of large sectors of the world population, with dramatic effects caused not only by the health risks of COVID-19, but also by its psychological and social impacts. The World Health Organization [1] renamed it COVID-19 and on 11 March 2020 declared a state of pandemic. During the first wave of the pandemic, Spain was particularly affected by the spread of the virus. The first case was reported on 28 February and the curve of new cases increased exponentially. To reduce the risk of viral transmission at the national level, the Spanish Government (BOE, 2020) [2] declared a state of emergency from 14 March to 26 April 2020. During this period, citizens were allowed to go out only for the purchase of essential items (e.g., food, medicine), attend health centers, go to work (only for jobs considered essential, such as food suppliers), return to usual residence, care for dependents such as young children or disabled family members, and other force majeure events. In April, the curve of people infected with COVID-19 began to flatten, with 7940 reported new cases per day at the beginning of April, decreasing to 1631 by the end of the month [3]. Measures to reduce the spread of COVID-19 led to a disruption of normal daily life, social interactions, employment, and leisure activities.

Based on research on the psychological impact of previous outbreaks of coronavirus infections, such as SARS and MERS, the occurrence of psychological distress and symptoms 
of mental illness have been outlined in recent articles [4,5]. A recent review [6] on the psychological impact of lockdown highlighted its negative, potentially long-lasting impact on psychological health. These negative effects can be amplified by stressors occurring both during and after lockdown (e.g., duration, lack of information, financial loss).

At the beginning of the COVID-19 outbreak, most of the published articles were from China [7]. Using a survey procedure, Wang et al. [8] revealed that $53.8 \%$ of respondents reported a psychological impact of the outbreak, $16.5 \%$ reported moderate to severe depressive symptoms, $28.8 \%$ reported moderate to severe anxiety symptoms, and $8.1 \%$ reported moderate to severe stress levels. In a nationwide survey $(n=52,730)$, Qiu et al. [9] reported that $35 \%$ of the respondents experienced mild to severe COVID-19 peritraumatic distress. The first systematic review and meta-analysis, conducted with 17 articles, revealed a high prevalence of stress $(29.6 \%)$, anxiety $(31.9 \%)$, and depression $(33.7 \%)$ in the general population [10]. More recent meta-analyses reported a prevalence rate of $25 \%$ of anxiety [11] and depression [12]. The prevalence of depression increased during the pandemic as much as sevenfold [12], stressing the impact of COVID-19 on mental health.

The first study conducted in Spain during the first stage of the COVID-19 outbreak explored the extent to which different variables (i.e., age, degree of concern, significant changes in daily life, environmental conditions, or leisure activities during lockdown) were associated with the psychological impact (anxiety, depression, and stress) caused by the pandemic. In regard to stress and depression, Spaniards showed moderate to severe levels (22\% and 30\%, respectively). Women and young adults were those who experienced the greatest psychological impact. The lower the household size, the better the mental health [13]. In another study [14] conducted in the north of Spain, more than a quarter of the participants reported symptoms of depression (27.5\%), anxiety (26.9\%), and stress $(26.5 \%)$. Furthermore, the study revealed that stress, anxiety, and depression levels were higher when measured two to three weeks after the beginning of lockdown. In relation to gender, men showed higher levels of depression than women. Moreover, young adults (18-30 years) and middle-aged adults (31-59 years) showed higher levels of stress, anxiety, and depression than older adults (60-82 years). In relation to the variables that could have a predictive character of psychological stress in a Spanish population, Gómez-Salgado et al. [15] reported that being female, working outside the home, the perception of poor health, living in close contact with an infected person, and the number of symptoms are the variables that have most impact on psychological distress. Imperative preventive measures implemented by Governments to control the spread of the virus also become a source of stress, leading to anxiety and extreme distress.

Most studies focusing on the mental health outcomes of the COVID-19 pandemic used self-report questionnaires that assessed anxiety, depression, and posttraumatic stress symptoms [16]. In many cases these were well-established and validated instruments that do not explicitly relate to the pandemic situation. This makes it difficult to distinguish between already existing mental health conditions and those produced by the pandemic. Other studies used tools developed "ad hoc", which limit the generalizability of the results. A third alternative is the use of pandemic-specific scales. These scales allow a rapid detection of COVID-related stress symptoms, facilitating more efficient resource allocation of public mental health support by prioritizing assistance to the most affected population groups. Some of these questionnaires are the Fear of COVID-19 Scale (FCV-19S) [17], the Coronavirus Anxiety Scale (CAS, Lee, 2020) [18], the COVID-19 Phobia Scale (C19 P-S [19], and the COVID-19 Peritraumatic Distress Index (CPDI [9], see [20] for a review. Within these tools, the CPDI probably captures the COVID-related psychological distress most comprehensively, as it incorporates symptoms of a broad array of mental health syndromes and pathologies [20].

The CPDI has been used in several countries, keeping in mind that the predictors of distress during the COVID-19 pandemic may vary across different cultures. Ramasubramanian et al. [21] explored the psychological impact in Indian citizens and reported that $77.2 \%$ of the respondents had low or no distress, $20.2 \%$ had mild to moderate stress, and only $2.7 \%$ had 
severe stress. In a study conducted in Iran [22], the mean score of CPDI was higher than the results reported in China; $47 \%$ and $14.1 \%$ of the Iranian adults experienced mild to moderate and severe psychological distress, compared to $29.3 \%$ and $5.1 \%$ respectively in China. In Germany, Liu and Heinz [23] reported an average CPDI score (Mean $=21.9$, $\mathrm{SD}=12.6) 1.8 \%$ lower than that of the above-mentioned China-based sample (Mean $=23.7$, $\mathrm{SD}=15.4)$. In the German sample, $24 \%$ of respondents reported psychological distress ( $20.6 \%$ with mild stress and $3.6 \%$ severe stress), substantially lower rates than in the Chinese sample where $34.4 \%$ of the respondents reported distress (29.3\% mild and $5.1 \%$ severe). According to the authors, this difference might reflect a comparatively higher COVID-19 testing rate in Germany, which may confer a sense of security. In Italy, Constantiny and Mazzotti [24] assessed the prevalence of peritraumatic distress using the CPDI to compare their results with those of Qiu et al. [9]. The CPDI score obtained in the Italian male subsample was slightly lower than that of the Chinese (China, mean $=21.41$, SD 15.93 vs. Italy, mean $=18.61, \mathrm{SD}=12.20)$, but the mean scores of the female subsamples were very similar. Overall, it seems that being female constitutes an important risk factor for developing COVID-related stress symptoms. A recent Italian large-scale study with 20,158 participants found that higher CPDI scores were significantly associated with gender, being two-fold in women in comparison to men [25]. Similar results were found in Chinese [9], Brazilian [26], and Bangladeshi [27] samples. Furthermore, it seems that the clinical distress scores remain constant over time. In a longitudinal study, Megalakaki and colleagues [28] compared the CPDI responses of French participants from the initial phase of the pandemic, when societies were overwhelmed by the sudden outbreak, with those provided several months later, when strategies were established to deal with the situation. As expected, once societies regained a certain control over the situation, the overall CPDI scores declined at follow-up. However, after accounting for the effect of the baseline levels, the CPDI scores still predicted $43 \%$ to $47 \%$ of the prevalence of posttraumatic stress, depression, and anxiety, confirming its utility for the detection of potentially clinical mental health issues.

Regarding the psychometric properties of the CPDI, several studies from different countries provided the Cronbach's alpha for internal consistency and reliability [21-30]. Megalakaki et al. [28] reported the Cronbach's alpha in a French sample for pretest and posttest measures, together with the stability effect. On the other hand, Costantini and Mazzotti [24] reported the construct validity data for the CPDI in an Italian sample, which was analyzed by means of the correlations between the CPDI scores and three dimensions (Intrusion, Avoidance and Hyperarousal) of the revised Impact of Event Scale [31]. The development of the CPDI was based on diagnostic guidelines for specific phobias and stress disorders and includes items relating to anxiety, depression, specific phobias, cognitive change, avoidance and compulsive behavior, physical symptoms, and loss of social functioning [9]. Given the variety of symptoms assessed in the questionnaire, and despite the widespread use of the CPDI scale, it is surprising that the factorial structure of the CPDI remains largely unexplored. To our knowledge, only one study has conducted a confirmatory factor analysis on the CPDI to validate the tool in an Italian population [32].

Given that the CPDI could constitute a promising tool for a rapid detection of mental health issues in the population, the present work had three main objectives:

(1) To investigate the factorial structure of the CPDI via exploratory (EFA) and confirmatory factor analysis (CFA) and validate the questionnaire in a Spanish sample;

(2) To quantify the prevalence and severity of COVID-related psychological distress in the Spanish population; and

(3) To analyze age and gender differences in relation with the factorial structure of the questionnaire.

\section{Materials and Methods}

\subsection{Participants}

Participants were recruited through postings on social media and snowball sampling. The lockdown measures imposed during the pandemic did not interfere with the 
data collection process. Inclusion criteria were to reside in Spanish territory and to be more than 18 years old. Exclusion criteria was not to have completed the CPDI. Of the 1463 participants who began the questionnaire, 1094 completed it, yielding a response rate of $74.8 \%$. Thus, the final sample was composed of 1094 Spanish adults (241 males, $\mathrm{M}_{\mathrm{age}}=52.55, \mathrm{SD}=14.19$, range $=18-83$ years). Table 1 provides a description of the socio-demographic variables of the sample.

Table 1. Description of socio-demographic background variables. Percentages and SDs are shown in parentheses.

\begin{tabular}{|c|c|c|c|}
\hline Variable & Level & $n(\%)$ & $\mathrm{M}(\mathrm{SD})$ \\
\hline \multirow[t]{2}{*}{ Gender } & Men & $241(22 \%)$ & \\
\hline & Women & $853(78 \%)$ & \\
\hline \multirow[t]{4}{*}{ Age } & Total & & $52.55(14.19)$ \\
\hline & 18 to 39 years & $228(20.8 \%)$ & $31.69(5.87)$ \\
\hline & 40 to 59 years & $468(42.8 \%)$ & $49.82(5.88)$ \\
\hline & $\geq 60$ years & $398(36.4 \%)$ & $67.04(5.22)$ \\
\hline \multirow[t]{6}{*}{ Education ${ }^{1}$} & Total & & $5.2(1.18)$ \\
\hline & University degree or higher & $658(60.1 \%)$ & \\
\hline & High school diploma & $181(16.5 \%)$ & \\
\hline & Vocational training & $134(12.2 \%)$ & \\
\hline & Senior high school & $62(5.7 \%)$ & \\
\hline & Junior high school or less & $59(59 \%)$ & \\
\hline \multirow[t]{5}{*}{ Employment status ${ }^{2}$} & Total & & $1.46(0.81)$ \\
\hline & Employed & $747(68.3 \%)$ & \\
\hline & Unemployed or housekeeper & $66(6 \%)$ & \\
\hline & Student & $22(2 \%)$ & \\
\hline & Retired & $259(23.7 \%)$ & \\
\hline \multirow[t]{3}{*}{ Place of residence } & Autonomous Community of Madrid & $538(49.2 \%)$ & \\
\hline & Rest of Autonomous Communities & $379(34.6 \%)$ & \\
\hline & $\mathrm{N} / \mathrm{A}$ & $177(16.2)$ & \\
\hline \multirow[t]{8}{*}{ Professional occupation ${ }^{3,4}$} & Armed forces occupations & $6(0.8 \%)$ & \\
\hline & Clerical support workers & $169(22.6)$ & \\
\hline & Craft and related trades workers & $7(0.9 \%)$ & \\
\hline & Elementary occupations & $32(4.3 \%)$ & \\
\hline & Managers & $13(1.7 \%)$ & \\
\hline & Professionals & $317(42.4 \%)$ & \\
\hline & Service and sales workers & $76(10.1 \%)$ & \\
\hline & Technicians & $87(11.6 \%)$ & \\
\hline
\end{tabular}

${ }^{1}$ Level of educational attainment was defined as follows: $1=$ below primary education, $2=$ junior high school, $3=$ senior high school, $4=$ vocational training, $5=$ high school diploma, $6=$ university degree or higher. ${ }^{2}$ Employment status was defined as follows: $1=$ employed, $2=$ retired, $3=$ student, $4=$ unemployed or housekeeper. ${ }^{3}$ Only active workers were included in this section $(n=747) .{ }^{4}$ Professional occupations were categorized according to the 10 mayor groups of the International Standard Classification of Occupations (ISCO).

\subsection{Instruments}

To assess psychological distress, we used the Spanish translation of the COVID-19 Peritraumatic Distress Index, CPDI [9]. This instrument is a self-report questionnaire with 24 items that assess COVID-19 peritraumatic distress symptoms. The questionnaire was developed to evaluate COVID-19 distress in China. The authors provided us with the English version, which was translated into Spanish using the forward-backward translation procedure. This method consists in re-translating the translated text back into the source language. No significant inconsistencies were found between the back-translation and the original document. The questionnaire examines the frequency of anxiety, depression, specific phobias, cognitive change, avoidance, compulsive behavior, physical symptoms, and loss of social functioning in recent weeks. Participants rate each item on a 5-point Likert scale ranging from 0 (never) to 4 (most of the time). Scores are summed (total score range 0-100) with higher scores indicating higher COVID-19 peritraumatic distress. Chinese normative data reveal the following ranges for the total score: 28-51 mild to 
moderate distress and $\geq 52$ severe distress. The CPDI showed satisfactory reliability and content validity.

\subsection{Procedure}

We used a cross-sectional survey design to assess the participants' psychological response to the COVID-19 pandemic using an anonymous online questionnaire. The online survey was prepared on the Qualtrics Software [33] and responses were collected from 8 May to 25 June 2020 . The survey was distributed via an anonymous link to the survey URL and anyone who clicked on the link was able to take the survey. A progress bar indicated the percentage that had been completed and respondents could save and continue the survey for one week. The link could only be used once per participant. The survey data was recorded automatically by the Qualtrics platform. All the participants read a description of the study protocol before responding to the survey and were informed that they could discontinue their participation in the study at any point.

\subsection{Ethical Considerations}

The study was conducted in accordance with the Declaration of Helsinki. The Ethical Committee Board of Research of the Universidad Nacional de Educación a Distancia (UNED) approved the study. The approval document was signed by the President of the Committee and Vice-Rector of Research of the University. Participation was entirely voluntary. All subjects gave their informed consent for inclusion before they participated in the study and gave their explicit informed consent for the confidential use and processing of the data, in accordance with the current laws regarding the protection of personal data [34]. Data were stored anonymously with an assigned number so that it was not possible to identify the participants.

\subsection{Data Analysis}

An initial descriptive analysis was conducted by calculating the means and frequency of the variables on the total sample, the subsamples of men and women, and by age group: young adults (18-39), middle-aged adults (40-59), and older adults (over 60). For the Spanish sample, we calculated the mean $(\bar{X})$ and SD for the total sample. Participants who scored in the semi-open interval $[\bar{X}, \bar{X}+S D)$ were considered in the mild to moderate range of distress, and those who scored above $\bar{X}+S D$ were regarded as coming within the severe range. Exploratory factor analysis (EFA) and confirmatory factor analysis (CFA) were conducted to examine the factor structure of CPDI in the Spanish sample. To this end, participants were split into two subsamples of equal size: Subsample $1(n=547)$ was used for EFA, and Subsample $2(n=547)$ for CFA, which was conducted using the lavaan package for R [35]. Findings from the hypothesized measurement model were evaluated using common indices and their cut-off points: Tucker-Lewis index (TLI) and comparative fit index (CFI) with values of $\geq 0.90$ and $\geq 0.95$ indicating adequate and good model fit, respectively; standardized root mean square residual (SRMR) and root mean square error of approximation (RMSEA), with values below or equal to $0.10,0.08$, and 0.05 indicating acceptable, adequate, and good model fit, respectively [36]. In addition, a cluster analysis was performed on the CPDI data used for the EFA subsample. A $2 \times 3$ ANOVA was performed with gender (male vs. female) and age (young, middle-aged, and older adults) as between-subjects factors using the factor scores of the CPDI as the dependent variable.

\section{Results}

The participants' CPDI scores were as follows: 636 respondents had no distress $(27.90 \%$ and $72.0 \%$ for men and women respectively), 279 participants reported mild/moderate distress (17.90\% and $82.0 \%$, for men and women, respectively), and 179 participants came in the severe distress range (7.26\% men and $92.7 \%$ women). Table 2 displays mean CPDI scores as a function of gender, age group, and range of COVID-19 distress. 
Table 2. Mean values of CPDI scores as a function of gender, age group, and range of COVID-19 distress. SDs are shown in parentheses.

\begin{tabular}{lcc}
\hline & $\boldsymbol{n}(\mathbf{\%})$ & $\mathbf{M}(\mathbf{S D})$ \\
\hline $\begin{array}{l}\text { Total Sample } \\
\text { Gender }\end{array}$ & 1094 & $26.15(15.28)$ \\
$\quad$ Men & $241(22 \%)$ & $19.75(12.37)$ \\
$\quad$ Women & $853(77 \%)$ & $27.95(15.53)$ \\
Age groups & & \\
$\quad$ Young Adults & $228(20.8)$ & $26.46(15.69)$ \\
$\quad$ Middle-aged Adults & $468(42.7)$ & $29.01(16.23)$ \\
$\quad$ Older Adults & $398(36.3)$ & $22.61(13.06)$ \\
Range of COVID-19 distress & & \\
$\quad$ No Distress & $636(58.13)$ & $15.59(5.93)$ \\
$\quad$ Mild to moderate & $279(25.50)$ & $33.11(4.29)$ \\
$\quad$ Severe & $179(16.36)$ & $53.84(9.50)$ \\
\hline
\end{tabular}

\subsection{Exploratory Factor Analysis}

To investigate the underlying factorial structure of the Spanish version of the CPDI questionnaire, we used Exploratory Factor Analysis (EFA). We based the analysis on a subsample $(n=547)$. All 24 items of the CPDI were subjected to a principal axis factoring and varimax rotation, Kaiser-Meyer-Olkin value was 0.91 and Bartlett's test of sphericity was significant, Chi-square $(\mathrm{df}=253)=4617.65, p<0.001$, supporting a rationale for performing EFA. In a parallel analysis [36], an eigenvalue greater than 1 and the elbow on the scree plot was used to decide the optimal number of factors.

The parallel analysis approach compares the eigenvalues of covariance matrices, one for the 24 data items and one based on white noise. The eigenvalues and the scree plot are shown in Figure 1. The results suggest a two-factor solution. After rotation, the first factor (Stress symptoms) accounted for $34.51 \%$ of the total variance of CPDI, while the second factor (COVID-19 Information) accounted for $14.68 \%$ of the total variance. The Stress symptoms dimension has 15 items related to negative mood, cognitive change, and physical symptoms. The COVID-19 Information factor has eight items related to attitudes to news and information in the media about the COVID-19 pandemic. Items and factor loading for the rotated factors are shown in Table 3. Factors with loadings smaller than 0.25 were omitted to improve clarity. Cronbach's alpha for the Spanish CPDI total score was 0.88 after deleting item number 5 due to its low factor loading.

Parallel Analysis Scree Plots

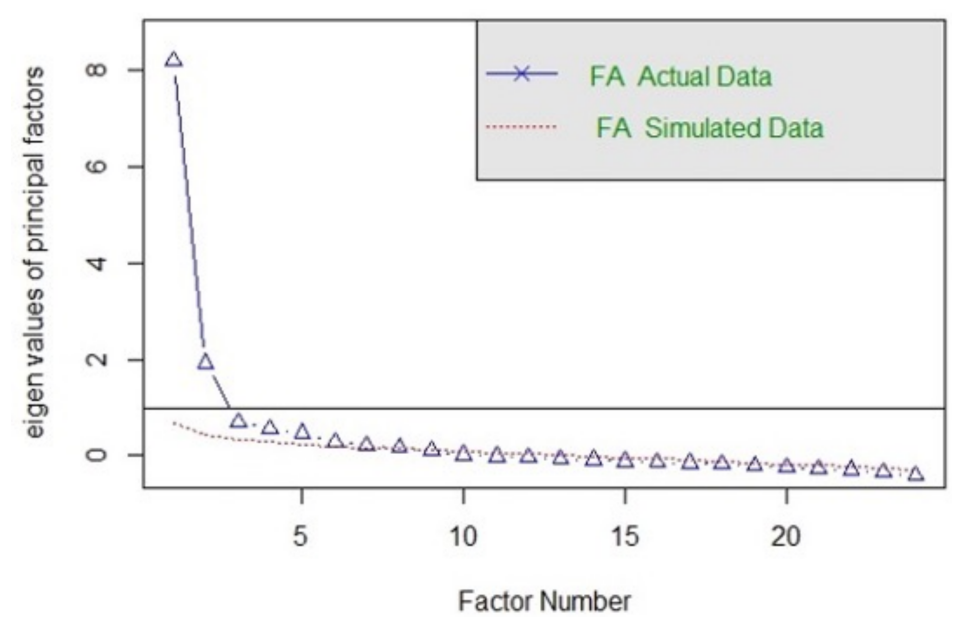

Figure 1. Parallel analysis scree plots. 
Table 3. Factor loadings for the rotated factor.

\begin{tabular}{|c|c|c|c|}
\hline \multirow[t]{2}{*}{ Items } & \multicolumn{2}{|c|}{ Factor Loading } & \multirow[t]{2}{*}{ Communality } \\
\hline & 1 & 2 & \\
\hline 15. Due to feelings of anxiety, my reactions are becoming sluggish & 0.811 & & 0.681 \\
\hline 16. I find it hard to concentrate & 0.772 & & 0.602 \\
\hline 14. I feel tired and sometimes even exhausted & 0.770 & & 0.593 \\
\hline 17. I find it hard to make any decisions & 0.727 & & 0.568 \\
\hline 1. Compared to usual, I feel more nervous and anxious & 0.703 & & 0.542 \\
\hline 18. During this COVID-19 period, I often feel dizzy or have back pain and chest distress & 0.715 & & 0.519 \\
\hline 13. I am more irritable and have frequent conflicts with my family & 0.701 & & 0.495 \\
\hline 4. I feel empty and helpless no matter what I do & 0.657 & 0.308 & 0.527 \\
\hline $\begin{array}{l}\text { 19. During this COVID-19 period, I often feel stomach pain, bloating, and other } \\
\text { stomach discomfort }\end{array}$ & 0.612 & & 0.380 \\
\hline 20. I feel uncomfortable when communicating with others & 0.634 & & 0.416 \\
\hline 23. I lost my appetite & 0.590 & & 0.363 \\
\hline 7. I am losing faith in the people around me & 0.437 & & 0.241 \\
\hline 24. I have constipation or frequent urination & 0.422 & & 0.178 \\
\hline 21. Recently, I rarely talk to my family & 0.366 & & 0.138 \\
\hline $\begin{array}{l}\text { 22. I cannot sleep well. I always dream about myself or my family being infected } \\
\text { by COVID-19 }\end{array}$ & 0.350 & 0.385 & 0.271 \\
\hline 12. I avoid watching COVID-19 news, since I am scared to do so & 0.332 & & 0.113 \\
\hline 6. I feel helpless and angry about people around me, governors, and media & 0.331 & 0.338 & 0.244 \\
\hline $\begin{array}{l}\text { 8. I collect information about COVID-19 all day. Even if it's not necessary, } \\
\text { I can't stop myself }\end{array}$ & & 0.720 & 0.518 \\
\hline 11. I am constantly sharing news about COVID-19 (mostly negative news) & & 0.654 & 0.439 \\
\hline $\begin{array}{l}\text { 3. I can't stop myself from imagining myself or my family being infected and feel terrified } \\
\text { and anxious about it }\end{array}$ & 0.315 & 0.632 & 0.498 \\
\hline $\begin{array}{l}\text { 2. I feel insecure and bought a lot of masks, medications, sanitizer, gloves and/or other } \\
\text { home supplies }\end{array}$ & & 0.614 & 0.413 \\
\hline 9. I will believe the COVID-19 information from all sources without any evaluation & & 0.612 & 0.375 \\
\hline $\begin{array}{l}\text { 10. I would rather believe in negative news about COVID-19 and be skeptical about } \\
\text { the good news }\end{array}$ & & 0.552 & 0.390 \\
\hline
\end{tabular}

Note. Items with loading $<0.25$ were omitted.

\subsection{Confirmatory Factor Analysis}

The two-factor structure obtained in the EFA was tested on the second subsample of 547 participants. We conducted CFA using the lavaan package (version 0.6-7) under $\mathrm{R}$ version 4 [35]. The estimation method used was Weighted Least Square (WLS). Absolute fit indices of the CFA for the Spanish CPDI were $\frac{\chi^{2}}{d f}=4.59$, RMSEA $=0.07, G F I=0.845$, $A G F I=0.813, R M R=0.76$ and $S R M R=0.060$; incremental fit indices were NFI $=0.828$, $N N F I=0.844$, and CFI $=0.859$, while parsimony fit indices were PGFI $=0.701$ and $P N F I=0.749$. We observed that only RMSEA, and SRMR indices were adequate and that the other indices were near the cutoff values usually considered to indicate a good fit, but they did not cross those thresholds. Using the modification indices to find a better fit was not justified theoretically because we were trying to validate the structure found in EFA with the CFA in a new sample. To this end, we modified the CFA model with the modification indices greater than 10. Although the fit indices increased, the qualitative fit results did not change. Figure 2 shows the standardized path coefficients and error variances of the original model. The standardized factor loadings ranged from 0.42 to 0.88 for the stress symptoms dimension, and from 0.47 to 0.87 for the information dimension. The correlation between the two latent variables (Stress and Information) was high (0.76). 


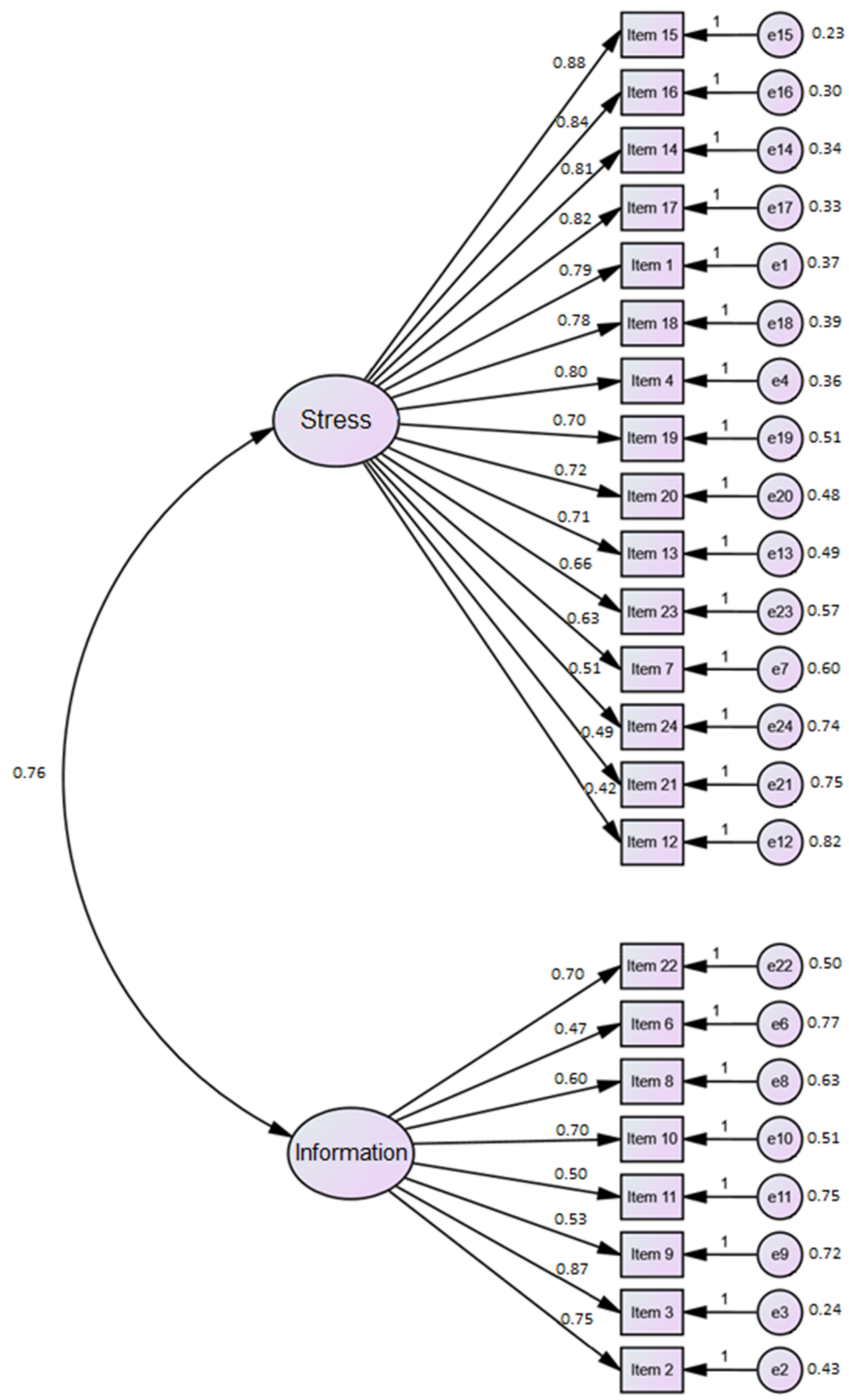

Figure 2. The standardized factor loadings and error variances for the hypothesized model.

\subsection{Gender and Age Group Differences on Psychological Distress}

We performed two $3 \times 2$ ANOVAs on the factor scores for Stress symptoms and COVID-19 information with Gender (men, women) and Age (Young, Middle-aged, and Older adults) as between-subjects factors. Participants were coded as young if they were aged between 18 and 39, as middle-aged if they were aged between 40 and 59, and older adults if they were aged over 60 . These analyses were performed on the total sample. 
The results for Stress symptoms showed a main effect of Gender $[(F(1,1088)=57.029$, $\left.\left.M S e=0.856, p<0.001, \eta_{p}^{2}=0.05\right)\right]$ and a main effect of Age $[(F(2,1088)=36.182$, $\left.\left.M S e=0.856, p<0.001, \eta_{p}^{2}=0.062\right)\right]$. As shown in Figure 3, women scored higher than men in all age groups, and older adults scored lower than young and middle-aged participants $(p<0.05)$, while there was no difference between these two groups $(p>0.05)$.

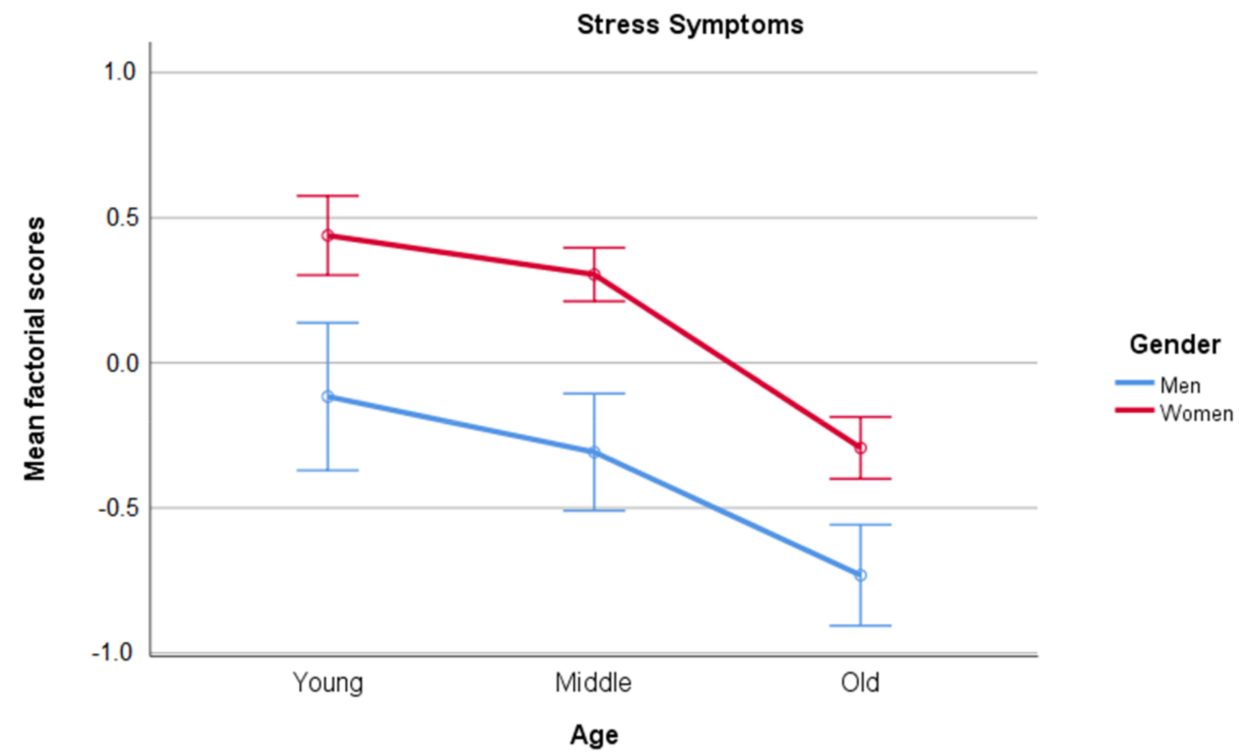

Figure 3. Mean scores and confidence interval (95\%) for factor scores in Stress symptoms as a function of participants' Gender and Age.

Regarding the factor scores for Information, only the main factor of Age was statistically significant $\left[\left(F(2,1088)=28.464, M S e=0.948, p<0.001, \eta_{p}^{2}=0.05\right)\right]$. Pair-wise comparisons showed that the three age groups differed statistically ( $p s>0.05)$. Older adults had the highest scores on COVID-19 Information, followed by middle-aged adults, and young adults had the lowest scores. The results are displayed in Figure 4.

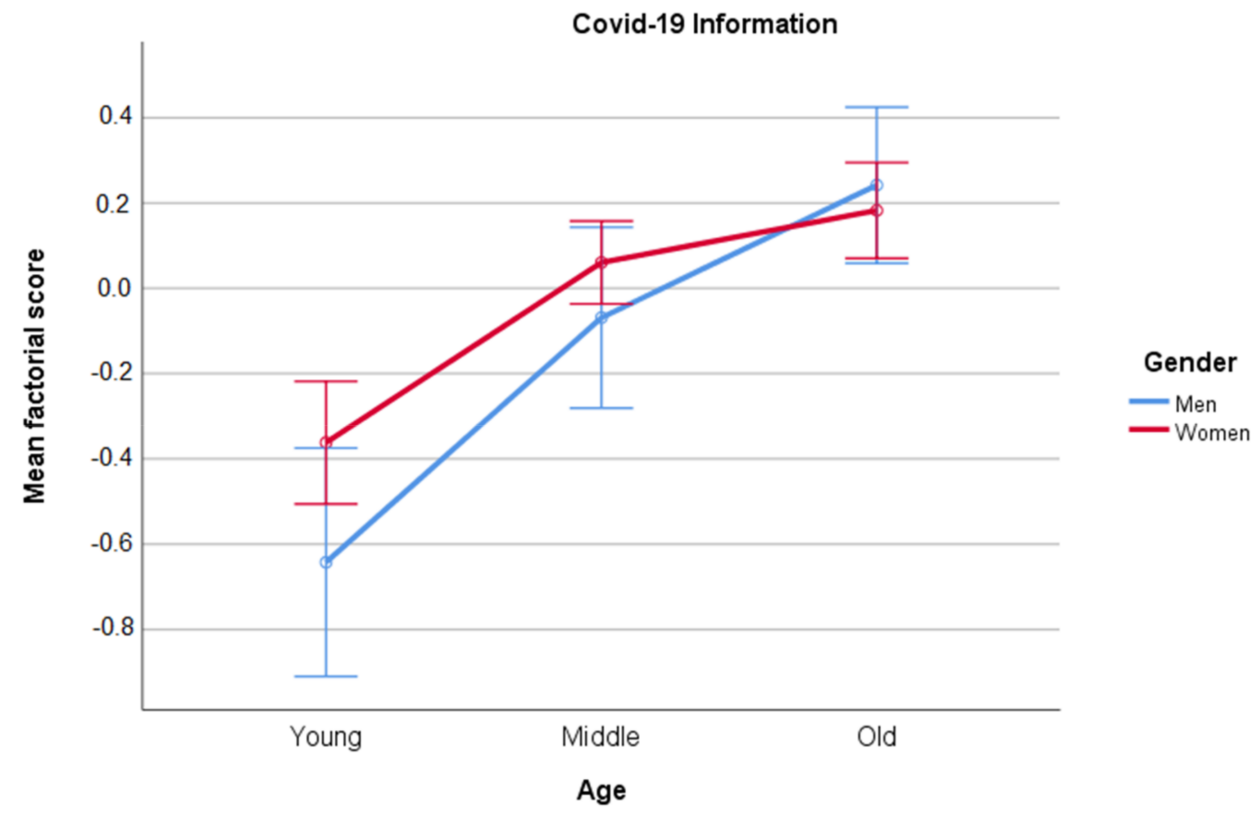

Figure 4. Means and confidence interval (95\%) of factor scores for COVID-19 Information as a function of Gender and Age. 


\subsection{Clustering}

To understand the meaning of the factor scores obtained in EFA and CFA, we clustered the CPDI data used in EFA with a Gaussian mixture model (GMM) including the whole sample $(n=1094)$. This clustering technique has excellent generalizability in that each participant can uniquely and easily be mapped to a different cluster, and each point in the coordinate space is assigned a probability of being in any cluster. Mathematically, several Gaussian distributions were fitted to the density of data points in the two-dimensional factor space. We used the mclust (version 5.4.6) for $\mathrm{R}$ to model the data [37]. The number of clusters was determined separately using the Bayesian Information Criterion (BIC) and the Rand index using the ellipsoidal equal shape and orientation model. The results showed four clusters of participants (Figure 5) with a log-Likelihood of -2829.25 , BIC equal to -5798.455 , and ICL equal to -6366.736 . See Figure 5.

\section{Cluster analysis of factorial scores}

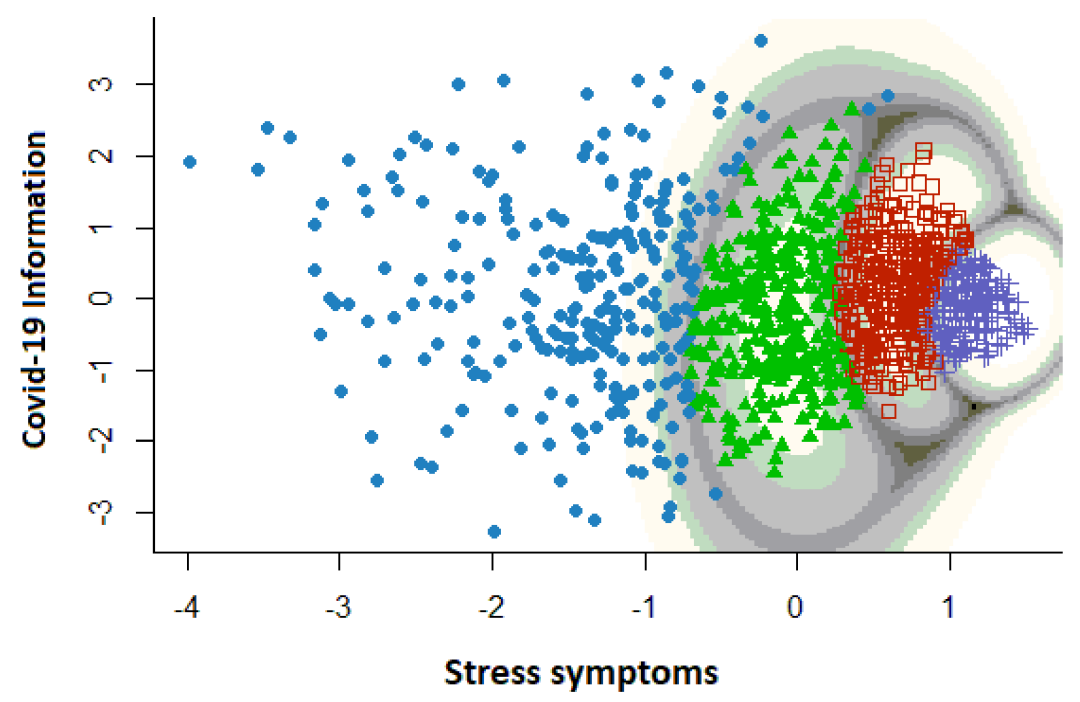

Figure 5. Results of the cluster analysis of the CPDI data conducted with the whole sample.

The first factor (distress symptomatology) showed an ordered pattern of the four groups from lower to higher distress, while the second factor (COVID-19 Information) showed approximately the same mean for each cluster (around 0 ) but with different variance.

\section{Discussion}

In this study, we investigated the factorial structure of the CPDI via exploratory (EFA) and confirmatory factor analysis (CFA) and validated the tool in a Spanish sample. To our knowledge, the present study is the first to use a comprehensive scale making it possible to capture different aspects of psychological distress related to the COVID-19 pandemic in a Spanish sample. For this purpose, two authors of the present paper translated into Spanish and adapted the COVID-19 Peritraumatic Distress Index (CPDI). We then tested its psychometric properties conducting an exploratory factor analysis (EFA), followed by a confirmatory factor analysis (CFA) of the structure found in the EFA conducted with a different sample. The results indicated that the Spanish adaptation of CPDI has a two-factor structure, with good internal consistency and reliability. The first factor (Stress symptoms) contains items related to psychological distress, whereas the second factor (COVID-19 Information) is related to different constructs associated with negative information in social media. The only study that had been conducted to date a confirmatory factor analysis on the CPDI [32] found a one-factor solution with 19 items, after eliminating items number $5,8,9,10$, and 11 , which did not comply with the item loading criteria $(\geq 0.32)$. However, the dimension choice for the CPDI in our study, based on the elbow of 
the scree plot and the eigenvalues of the factors, was a two-factor solution vs. a one-factor solution. We also removed item number 5 from the analysis due to its low factor loading, while items $8,9,10$, and 11 were maintained and loaded into the second factor above 0.30 (COVID-19 Information factor). Whereas the first factor (Stress symptoms) showed a high congruency between the Italian and Spanish samples, the second factor (COVID19 Information) seemed to be less defined. Nonetheless, the second factor still provides valuable information about the influence of COVID-19-related news on psychological well-being. The cluster analysis performed with the factorial scores of the two CPDI factors (Stress symptoms and COVID-19 Information) revealed four clearly defined groups. These groups were defined basically as a function of the stress symptomatology, arranged from low to high degree of stress symptoms. These four clusters did not differ in the COVID-19 Information factor. The results also showed that the higher the stress symptomatology, the more homogeneous were the groups.

Concerning the prevalence and severity of COVID-related psychological distress in the Spanish population and based on the cut-off values of distress in CPDI, in our Spanish sample, 279 participants $(25.5 \%)$ reported mild to moderate distress and 179 participants (16.36\%) experienced severe distress, compared to 52.0\% and 18.8\% in Brazil [26], 47.0\% and $14.1 \%$ in Iran [22], and $29.3 \%$ and 5.1\% in China [9]. The average CPDI score of our Spanish-based sample (Mean $=26.15, \mathrm{SD}=15.28)$ was higher than that reported in China $($ Mean $=23.65, \mathrm{SD}=15.45)$, Italia $($ Mean $=18.61, \mathrm{SD}=12.2)$, and Germany $($ Mean $=21.9$, $\mathrm{SD}=12.6$ ), but lower than that reported in Brazil (Mean $=37.6, \mathrm{SD}=15.22$ ) [26], Iran (Mean $=34.54, \mathrm{SD}=14.92)$ [22], and France $(24.01, \mathrm{SD}=12.76)$ [28]. Furthermore, we found gender differences in the mild/moderate distress range $(17.92 \%$ and $82.07 \%$ for men and women, respectively) and the severe distress range ( $7.26 \%$ and $92.73 \%$ for men and women, respectively). These findings are in line with those obtained by other studies using the CPDI [9,23-27]. Furthermore, studies using instruments other than the CPDI to measure stress symptoms reported similar findings, with women experiencing higher levels of psychological distress than men $[8,13,15,38]$. It might be possible that females are more predisposed to express their emotional states. However, as these findings were reported across different cultures, more research is needed to understand what causes the gender differences.

In this study, we additionally analyzed the gender differences using the factorial scores of the CFA. The results revealed that the gender differences were only related to the Stress symptoms factor and not to the COVID-19 Information factor, independently of the age group. Women experienced more physical symptoms, negative mood, and behavioral changes than men, irrespectively of age. The absence of gender differences in the Information factor suggests that both, men and woman, are similarly reactive towards COVID-related information, but that this information might affect women more negatively. Our results indicate that with increasing age, people tend to be more susceptible for COVID-related information input. Paradoxically, this age-related increase in Information is not associated with an increase in stress symptoms, which are lower in older than in younger adults.

Age is an important risk factor for mortality due to COVID-19, increasing exponentially from 50 years on [39]. Although people over 60 should be more concerned about getting infected, because they are considered at high risk, in our sample participants over 60 showed lower levels of distress than young and middle-aged participants, with no difference between the latter groups. This result could be explained by the fact that older adults are less affected than other age groups by the economic impact of the pandemic (i.e., unemployment, reduced turnover, etc.), and carry less burden of family-related responsibilities. Furthermore, it seems that older people find it easier to relativize the traumatic impact due to their life-long experience. Our results on age differences are in line with those found by other studies. For example, García-Fernández et al. [40] found in a Spanish sample, that older adults were less vulnerable than younger participants to suffer from depression and acute stress, whereas no age differences were found in anxiety during the 
peak of the pandemic. Age-related differences were also found in a Canadian sample [41], with significantly lower mean scores for stress, anxiety, and depression in older than in younger adults.

Another study [42] examined the association between age, COVID-19 disruption, stress, and affect. In this study, middle-aged and older adults experienced less distress than younger adults in response to their perceived life disruptions caused by the pandemic. The authors suggest, that when faced with a stressor (global pandemic), middle-aged and older adults might regulate better their emotions, even when they perceive the stressor as disruptive. Therefore, older adults seem to adapt better to the crisis caused by the pandemic. In this sense, López et al. [43] investigated the psychological well-being (personal growth and purpose in life) experienced during the COVID-19 crisis in a Spanish sample of young-old (60-70 years) and old-old adults (71-80) and the variables associated. Although differences were found between both older age groups (young-old experienced more personal growth, but they did not experience more purpose in life than old-old), the results of this study showed that personal resources, such as resilience and gratitude, and less experiential avoidance, are related with greater levels of personal growth.

Regarding the Spanish adaptation of the CPDI, more research is needed to understand the discrepancy between the factorial solutions found in the Spanish and Italian samples. Although this discrepancy could be due to differences between samples, we think that they were due to intrinsic features of the questionnaire. In the present study, we found that even statistical indices that assessed the number of dimensions of the questionnaire did not agree. For example, the parallel analysis showed nine dimensions, while the scree plot showed two clear dimensions. We chose a two-factor solution as a compromise between the results of the scree plot, the eigenvalue value of 1 and the parallel analysis. The moderate fit indices in the CFA in our study also suggest that the factor solution for CPDI is inconclusive and that the items of the CPDI need to be reviewed in the European population.

\section{Limitations}

The present study is not without limitations. As data was only collected at one point in time, the results do not permit causal inferences to be drawn. To evaluate the impact of the pandemic outbreak on psychological well-being in terms of a change produced in the person, would need longitudinal data, especially from before the pandemic outbreak. Moreover, the procedure of data collection inherently implies sampling biases, as only those people who disposed of the necessary technical devices to complete the survey could participate. This could explain why our sample was biased towards a higher academic background. In our study, approximately half of the data came from the Autonomous Community of Madrid. This area was the most affected during the first wave of the pandemic, which could explain in part the greater participation in Madrid. However, the snowball-sampling method might accentuate biases, not only towards a geographical area, but also towards certain age groups or socio-demographic backgrounds. Moreover, the fit indices for the CFA model were just below the threshold value considered acceptable. The just below fit shows that there is potential for improvement in the CPDI scale in future studies.

\section{Conclusions}

Women experience more COVID-related distress than men, and the level of distress decreases with age. The gender differences in the CPDI scores are related with items associated with stress symptoms, but not with those associated with COVID-19 related information input. This suggest that, even though both genders are exposed to similar information about COVID-19, women might be more prone to process this information negatively. The CPDI constitutes a promising tool for capturing the psychological impact of the current health crisis and might be useful for a rapid detection of potential peritraumatic stress caused by the COVID-19 pandemic. Future studies should include the development of more comprehensive measures adding items about risk, vulnerability, and protective factors that contribute to psychological distress. 
Author Contributions: Conceptualization, M.P.J. and J.M.R. with the rest of the authors; methodology, all the authors; software, J.M.R.; validation, J.A.R. and S.B.; formal analysis, M.P.J., J.A.R., and J.M.R.; writing - original draft preparation, M.P.J. with the collaboration of the rest of the authors; writing-review and editing, S.B.; supervision, J.M.R. and S.B.; funding acquisition, S.B. and J.M.R. All authors have read and agreed to the published version of the manuscript.

Funding: The study is supported by grants from the Spanish Ministry of Economy and Competitiveness (grant \#PSI2016-80377-R) to S.B. and J.M.R., from the Council of Madrid (B2017/BMD-3688) to J.M.R., and by a grant of the European Community (H2020-SC1-DTH-03-2018, grant agreement $\mathrm{N}^{\mathrm{o}}$ 826506, sustAGE) to S.B. J.A.R. is supported by a Doctoral Fellowship from the Spanish Ministry of Economy and Competitiveness (grant \#BES-2017-079760).

Institutional Review Board Statement: The study was conducted according to the guidelines of the Declaration of Helsinki, and approved by the Institutional Review Board of the Universidad Nacional de Educación a Distancia (UNED).

Informed Consent Statement: Informed consent was obtained from all subjects involved in the study.

Data Availability Statement: Materials and data for this study are available on the project page located on the Open Science Framework (https:/ / osf.io/jkw6b/, accessed on 13 May 2021).

Acknowledgments: We would like to express our gratitude to Cristina Pérez Rojo for her help and to the volunteers who responded to our invitation to participate in the online study.

Conflicts of Interest: The authors declare no conflict of interest. The funders had no role in the design of the study nor in the writing of the manuscript.

\section{References}

1. World Health Organization. Who'Director-General's Opening Remarks at the Mission Briefing on COVID-19. Available online: https:/ / www.who.int/director-general/speeches/detail/who-director-general-s-opening-remarks-at-the-media-briefingon-Covid-19---11-march-2020 (accessed on 13 January 2021).

2. BOE. Boletín Oficial del Estado (BOE). Real Decreto 463/2020, de 14 de Marzo, por el que se Declara el Estado de Alarma Para la Gestión de la Situación de Crisis Sanitaria Ocasionada por el COVI-19. 2020. Available online: http://www.boe.es/eli/es/rd/20 20/o3/14/463 (accessed on 16 January 2021).

3. World Health Organization. WHO Coronavirus Disease (COVID-19) Dashboard. 2020. Available online: https://Covid19.who. int/table (accessed on 13 January 2021).

4. Chew, Q.H.; Wei, K.C.; Vasoo, S.; Chua, H.C.; Sim, K. Narrative synthesis of psychological and coping responses towards emerging infectious disease outbreak in the general population: Practical considerations for the COVID-19 pandemic. Singap. Med. J. 2020, 61, 350-356. [CrossRef]

5. Torales, J.; O’Higgins, M.; Castaldelli-Maia, J.M.; Ventriglio, A. The outbreak of coronavirus and its impact on global mental health. Int. J. Soc. Psychiatry 2020, 66, 317-320. [CrossRef] [PubMed]

6. Brooks, S.K.; Webster, R.K.; Smith, L.E.; Woodland, L.; Wessely, S.; Greenberg, N.; Rubin, G.J. The psychological impact of quarantine and how to reduce it: Rapid review of the evidence. Lancet 2020, 395, 912-920. [CrossRef]

7. Rajkumar, R.P. Covid-19 and mental health: A review of the existing literature. Asian J. Psychiatry 2020, 52, 102066. [CrossRef] [PubMed]

8. Wang, C.; Pan, R.; Wan, X.; Tan, Y.; Xu, L.; Ho, C.; Ho, R.C. Immediate psychological responses and associated factors during the Initial Stage of the 2019 coronavirus disease (COVID-19) epidemic among the general population in China. Int. J. Environ. Res. Public Health 2020, 17, 1729. [CrossRef] [PubMed]

9. Qiu, J.; Shen, B.; Zhao, M.; Wang, Z.; Xie, B.; Xu, Y. A nationwide survey of psychological distress among Chinese people in the COVID-19 epidemic: Implications and policy recommendations. Gen. Psychiatry 2020, 33, e100213. [CrossRef]

10. Salary, N.; Hosseinian-Far, A.; Jalali, R.; Vaisu-Raygani, A.; Rasoulpur, S.; Mohammadi, M.; Rasoulpoor, S.; Khaledi-Paveh, B. Prevalence of stress, anxiety, depression among the general population during the COVID-19 pandemic: A systematic review and meta-analysis. Glob. Health 2020, 16, 57. [CrossRef]

11. Santabárbara, J.; Lasheras, I.; Lipnicki, D.M.; Bueno-Notivol, J.; Pérez-Moreno, M.; López-Antón, R.; De la Cámara, C.; Lobo, A.; Gracia-García, P. Prevalence of anxiety in the COVID-19 pandemic: An updated meta-analysis of community-based studies. Prog. Neuropsychopharmacol. Biol. Psychiatry 2020, 109, 110207. [CrossRef]

12. Bueno-Notivol, J.; Gracia-García, P.; Olaya, B.; Lasheras, D.; López-Antónc, R. Prevalence of depression during the COVID-19 outbreak: A meta-analysis of community-based studies. Int. J. Clin. Health Psychol. 2021, 1. [CrossRef]

13. Rodríguez-Rey, R.; Garrido-Hernansaiz, H.; Collado, S. Psychological impact and associated factors during the initial stage of the coronavirus (COVID-19) pandemic among the general population in Spain. Front. Psychol. 2020, 11, 1540. [CrossRef] 
14. Ozamiz-Etxebarria, N.; Idoiaga Mondragon, N.; Dosil Santamaría, M.; Picaza Gorrotxategi, M. Psychological symptoms during the two of stages of lockdown in response to the COVID-19 outbreak: An investigation in a sample of citizens in northern Spain. Front. Psychol. 2020, 11, 1491. [CrossRef]

15. Gómez-Salgado, J.; Andrés-Villas, M.; Domínguez-Salas, S.; Díaz-Milanés, D.; Ruiz-Frutos, C. Related Health Factors of Psychological Distres During the COVID-19 Pandemic in Spain. Int. J. Environ. Res. Public Health 2020, 17, 3947. [CrossRef] [PubMed]

16. Talevi, D.; Pacitti, F.; Socci, V.; Renzi, G.; Alessandrini, M.C.; Trabbi, E.; Rossi, R. The COVID-19 outbreak: Impact on mental health and intervention strategies. J. Psychopathol. 2020, 26, 162-168. [CrossRef]

17. Ahorsu, D.K.; Lin, C.-Y.; Imani, V.; Saffari, M.; Griffiths, M.D.; Pakpourt, A.H. The fear of COVID-19 scale: Development and initial validation. Int. J. Ment. Health Addict. 2020. [CrossRef] [PubMed]

18. Lee, S.A. Coronavirus Anxiety Scale: A brief mental health screener for COVID-19 related anxiety. Death Stud. 2020, 44, 393-401. [CrossRef] [PubMed]

19. Arpaci, I.; Karatas, K.; Baloglu, M. The development and initial test for the psychometric properties of the COVID-19 Phobia Scale (C19P-S). Pers. Individ. Dif. 2020, 11, 164. [CrossRef]

20. Chandu, V.C.; Marella, Y.; Panga, G.S.; Pachava, S.; Vadapalli, V. Measuring the impact of COVIDCOVID-19 on mental health: A scoping review of the existing scales. Indian J. Psychol. Med. 2020, 42, 421-427. [CrossRef] [PubMed]

21. Ramasubramanian, V.; Mohandoss, A.A.; Rajendhiran, G.; Pandian, P.R.S.; Ramasubramanian, C. Statewide survey of psychological distress among people of Tamil Nadu in the COVID-19 pandemic. Indian J. Psychol. Med. 2020, 42, 368-373. [CrossRef]

22. Jahanshahi, A.A.; Dinami, M.M.; Madavani, A.N.; Li, J.; Zhan, S.X. The distress during the Covid-19 pandemic-More distressed than the Chinese and with different predictors. Brain Behav. Immun. 2020, 87, 124-125. [CrossRef]

23. Liu, S.; Heinz, A. Cross-Cultural Validity of Psychological Distress Measurement during the Coronavirus Pandemic. Pharmacopsychiatry 2020. [CrossRef]

24. Constantiny, A.; Mazzotti, E. Italian validation of Covid-19 Peritraumatic Distress Index and preliminary data in a sample of general population. Riv. Psichiatr. 2020, 55, 145-151. [CrossRef]

25. Bonati, M.; Campi, R.; Zanetti, M.; Cartabia, M.; Scarpellini, F.; Clavenna, A.; Segre, G. Psychological distress among Italians during the 2019 coronavirus disease (COVID-19) quarantine. BMC Psychiatry 2021, 21. [CrossRef] [PubMed]

26. Zhang, S.X.; Wang, Y.; Jahanshahi, A.A.; Li, J.; Schmitt, V.G.H. Early evidence and predictors of mental distress of adults one month in the COVID-19 epidemic in Brazil. J. Psychosom. Res. 2021, 142, 110366. [CrossRef] [PubMed]

27. Marzo, R.R.; Singh, A.; Mukti, R.F. A survey of psychological distress among Bangladeshi people during the COVID-19 pandemic. Clin. Epidemiol. Glob. Health 2021, 10, 100693. [CrossRef] [PubMed]

28. Megalakaki, O.; Kokou-Kpolou, C.K.; Vaudé, J.; Park, S.; Iorfa, S.K.; Cénat, J.M.; Derivois, D. Does peritraumatic distress predict PTSD, depression and anxiety symptoms during and after COVID-19 lockdown in France? A prospective longitudinal study. J. Psychiatr. Res. 2021, 137, 81-88. [CrossRef] [PubMed]

29. Shrestha, D.B.; Thapa, B.B.; Katuwal, N.; Shrestha, B.; Pant, C.; Basnet, B.; Mandal, P.; Gurung, A.; Agrawal, A.; Runiyar, R. Psychological distress in Nepalese residents during COVID-19 pandemic: A community level survey. BMC Psychiatry 2020, 20, 491. [CrossRef]

30. Abad, A.; da Silva, J.A.; de Paiva Teixeira, L.E.P.; Antonelli-Ponti, M.; Bastos, S.; Mármora, C.H.C.; Campos, L.A.M.; Paiva, S.; de Freitas, R.L.; da Silva, J.A. Evaluation of Fear and Peritraumatic Distress during COVID-19 Pandemic in Brazil. Adv. Infect. Dis. 2020, 10, 184-194. [CrossRef]

31. Weiss, D.S.; Marmar, C.R. The Impact of Event Scale-Revised. In Assessing Psychological Trauma and PTSD; Wilson, J.P., Keane, T.M., Eds.; Guilford Press: New York, NY, USA, 1997; pp. 399-411.

32. Landi, G.; Pakenham, K.I.; Boccolini, G.; Tossani, E. Health anxiety and mental health outcome during Covid-19 lockdown in Italy: The mediating and moderating roles of psychological flexibility. Front. Psychol. 2020, 11, 2195. [CrossRef]

33. Qualtrics. Qualtrics Software (Version 37,892) [Computer Software]; Qualtrics Research Suite: Provo, UT, USA, 2013.

34. Ley Orgánica 3/2018, de 5 de Diciembre, de Protección de Datos Personales y Garantía de los Derechos Digitales. BOE-A-201816673. Available online: https:/ / www.boe.es/eli/es/lo/2018/12/05/3/con (accessed on 13 January 2021).

35. Rosseel, Y. Lavaan: Latent Variable Analysis 2018. Available online: https: / /CRAN.R-project.org/package=lavaan (accessed on 11 January 2021).

36. Horn, J.L. A rationale and test for the number of factors in factor analysis. Psychometrika 1965, 30, 179-185. [CrossRef]

37. Scrucca, L.; Fop, M.; Murphy, T.B.; Raftery, A.E. Mclust 5: Clustering, classification and density estimation using Gaussian finite mixture models. $R$ J. 2016, 8, 205-233. [CrossRef]

38. Mazza, C.; Ricci, E.; Biondi, S.; Colasanti, M.; Ferracuti, S.; Napoli, C.; Roma, P. A Nationwide Survey of Psychological Distress among Italian People during the COVID-19 Pandemic: Immediate Psychological Responses and Associated Factor. Int. J. Environ. Res. Public. Health 2020, 17, 3165. [CrossRef] [PubMed]

39. Bonanad, C.; García-Blas, S.; Tarazona-Santabalbina, F.; Sanchis, J.; Bertomeu-González, V.; Fácila, L.; Ariza, A.; Núñez, J.; Cordero, A. The effect of age on mortality in Patiens with COVID-19. A Meta-Analysis with 611.583 subjects. J. Am. Med. Dir. Assoc. 2020, 21, 915-918. [CrossRef] [PubMed]

40. García-Fernández, L.; Romero-Ferreiro, V.; López-Roldán, P.D.; Padilla, S.; Rodriguez-Jimenez, R. Mental Health in Elderly Spanish People in Times of COVID-19 Outbreak. Am. J. Geriatr. Psychiatry 2020, 28, 1040-1045. [CrossRef] 
41. Nwachukwu, I.; Nkire, N.; Shalaby, R.; Hrabok, M.; Vuong, W.; Gusnowski, A.; Surood, S.; Urichuk, L.; Greenshaw, A.J.; Agyapong, V.I.O. COVID-19 Pandemic: Age-Related Differences in Measures of Stress, Anxiety and Depression in Canada. Int. J. Environ. Res. Public Health 2020, 17, 6366. [CrossRef]

42. Knepple Carney, A.; Graf, A.; Hudson, G.; Wilson, E. Age Moderates Perceived COVID-19 Disruption on Well-Being. Gerontologist 2021, 61, 30-35. [CrossRef]

43. López, J.; Perez-Rojo, G.; Noriega, C.; Carretero, I.; Velasco, C.; Martínez-Huertas, J.; López-Frutos, P.; Galarraga, L. Psychological well-being among older adults during the COVID-19 outbreak: A comparative study of the young-old and the old-old adults. Int. Psychogeriatr. 2020, 32, 1365-1370. [CrossRef] 